Espacio, Tiempo y Forma, Serie II, Historia Antigua, t. 23, 2010, págs. 259-278

\title{
Fiscalidad tributaria y post-tributaria en el Alto Imperio Romano
}

\author{
Tributarian and post-tributarian Fiscality in the High Roman \\ Empire
}

\author{
José CARlos JoRdÁn ReYes*
}

\begin{abstract}
RESUMEN
Con el tránsito de la República al Imperio, el sistema impositivo romano experimenta una profunda transformación. La fiscalidad cívica, regulada minuciosamente en el tributum, tiene su continuidad en las reformas fiscales emprendidas por Augusto, principalmente en el nuevo impuesto de sucesiones, la vicesima hereditatum y en la capitatio terrena. Se trata de un modelo tributario basado en la tradición republicana y con un fuerte sentido legal. A este modelo tributario se superpuso, como consecuencia de las necesidades de un Imperio en expansión, una fiscalidad ecléctica, con aportaciones de tributos de origen oriental, ajenas por completo al universo jurídico romano. Destinados en un principio a las provincias, fueron contaminando el sistema tributario romano en su conjunto. Estos tributos foráneos fueron a su vez contaminados por normas de Derecho romano, que les aportaron una naturaleza jurídica de la que solían carecer.
\end{abstract}

En resumen, a lo largo del alto Imperio se

\begin{abstract}
The shift from the Roman Republic to the Roman Empire brought about a profound transformation of the Roman tax system. The tax reforms set forth by Augustus, most particularly, the new heritage tax, the vicesima hereditatum, and the capitatio terrena, did not mean a complete break from the civic fiscality which the tributum carefully regulated. Augustus's system of taxation was based on the republican tradition and it had a strong sense of legality. Because of the needs of an expanding Empire, they added to this system of taxation an eclectic fiscality which included oriental taxes which had nothing to do with the Roman legal tradition. Originally designed for the provinces, these oriental taxes pervaded and corrupted the entire Roman system of taxation. In the same way, they were pervaded and corrupted in turn by the Roman law, which provided them with the legal character they lacked.
\end{abstract}

To sum up, the Roman High Empire developed a hybrid and complicated

* I.E.S. Mariano José de Larra, c/ Camarena, 181, 28047 Madrid. jocajore@ gmail.com 
va configurando un sistema tributario híbrido, complejo, de raíces romanas y orientales, con rasgos de fuerte juridicidad y al mismo tiempo con anomalías en su naturaleza jurídica y procedimental.

PALABRAS CLAVE: Tributum, Augusto, vicesima hereditatum, capitatio terrena, procedimiento, legalidad, fiscalidad ecléctica. system of taxation, consisting of Roman and oriental elements, which despite its powerful legal structure had also some irregularities/anomalies in its legal and procedural nature.

KEYWORDS:

Tributum, Augustus, vicesima hereditatum, capitatio terrena, procedure, legality, eclectic fiscality.

\section{PROCEDIMIENTO Y PROCEDIMIENTOS TRIBUTARIOS}

En la doctrina jurídico-tributaria, se entiende por procedimiento Tributario aquel que contiene la legislación que fija las condiciones, requisitos y términos que se deben cumplir en el proceso de tributación, tanto por parte del Estado como del contribuyente.

Tecnicismos aparte, y desde un punto de vista meramente histórico, podemos considerar el procedimiento tributario como los supuestos fácticos o legales que ordenan la actividad recaudatoria del Estado. Desde este punto de vista, ni siquiera son necesarios mecanismos de control de la legalidad, ni de revisión de los actos de la autoridad tributaria a instancias del contribuyente, ni mucho menos sujeción a principios de justicia o equidad. Tan sólo un cierto orden o método en la actuación pública que la haga más o menos previsible para el contribuyente. En otras palabras, una cierta seguridad jurídica. Quedan fuera del concepto de procedimiento, por tanto, las exacciones extraordinarias de carácter confiscatorio, las contribuciones de guerra, levas forzosas y otras prácticas similares.

Refiere Tácito cómo Julio Agrícola, gobernador de Britania, trataba de suavizar en la provincia «las exacciones de trigo y de tributos con la equidad en las cargas, suprimiendo lo que, ideado para lucrarse, se toleraba más penosamente que el propio tributo»'. La rebelión de Boudicca en Britania podría explicarse, de este modo, no tanto por el tributo en sí como por las corruptelas en su aplicación. Quizá es arriesgado atribuir tal perspicacia jurídica a los britanos, no así al propio Tácito, que reflejaría el sentir de un ciudadano romano ante la vulneración de los procedimientos legales.

Es evidente que, considerado de esta manera general, existió un procedimiento tributario - o varios - en Roma y su imperio, al igual que - aunque con

\footnotetext{
1 Tácito, Vida de Julio Agrícola, 19, 4.
} 
menor rigor- en el mundo griego y oriental ${ }^{2}$. La existencia de procedimientos tributarios no está en contradicción con su vulneración, incluso sistemática, como ocurrió a finales de la república, cuando al amparo de los conflictos civiles toda arbitrariedad tuvo cabida, tanto en Roma como en las provincias. Las verrinas de Cicerón son buena prueba tanto de la corrupción de los procedimientos tributarios como, sensu contrario, de la existencia de estos.

Hay que decir que, para la conciencia jurídica de los romanos, no existía más procedimiento legal que el civil. Sólo el ius civile estaba sometido a una serie de normas de rango legal, minuciosamente fijadas por la ley y la tradición a lo largo de los siglos, que prescribían los modos de actuar por parte de los sujetos jurídicos. Nunca se llegó a formular o sistematizar un auténtico procedimiento legal en el orden administrativo, ni en el tributario, ni siquiera en el penal.

Pero eso no quiere decir que no existieran estos procedimientos, porque los poderes públicos no actuaban en esos ámbitos de manera arbitraria y casuística. Aunque no siempre se aplicaban fórmulas de actuación predefinidas normativamente, se solía actuar con sujeción a normas y principios jurídicos, aunque no siempre explícitos. $\mathrm{Y}$ por eso podemos referirnos a estos procedimientos como a realidades y no como a meras construcciones doctrinales ex post. En Roma existían procedimientos tributarios, de la misma manera que en su lengua existían declinaciones: implícitamente.

Ahora bien, aunque partimos de la hipótesis de la existencia de procedimientos tributarios, tanto explícitos como implícitos, cuya existencia deja en evidencia a aquellas otras actuaciones ${ }^{3}$ fiscales no regladas (exacciones arbitrarias, confiscaciones, etc.), hay que convenir que entre unas y otras existe una amplia franja borrosa que no podemos encuadrar ni en una ni en otra categoría. Se trata de ingresos tributarios que, por faltarles algún elemento esencial, se integran en el sistema fiscal como figuras imperfectas del mismo.

La fiscalidad romana, por tanto, ocupa un amplísimo margen que abarca desde el máximo rigor legal y procedimental del tributum, hasta figuras impositivas situadas en los límites mismos de lo jurídico.

2 Sobre procedimiento civil romano, cf. A. Fernández de Buján, Derecho Público Romano. Recepción, jurisdicción y arbitraje, Madrid, 2007; Idem., Jurisdicción y arbitraje en Derecho Romano, Madrid, 2006; A. Ortega Carrillo de Albornoz, Derecho Privado Romano, Málaga, 2007; J. L. Murga, Derecho romano clásico II. El proceso, Zaragoza, 1989; J. Santa Cruz Teijeiro, Principios de Derecho procesal Romano, Valencia, 1947; T. Mommsen, Le droit publique romain, París, 1891. Sobre el derecho griego antiguo, cf. M. Gagarin, The Cambridge companion to ancient Greek law, Cambridge, 2005; I. Arnaoutoglou, Ancient Greek laws a sourcebook, Londres-Nueva York, 1998; E, M. Harris, Democracy and the rule of law in Classical Athens essays on law, society, and politics, Cambridge, 2006; A. Biscardi, Diritto Greco Antico, Turín, 1982; D. Kokkini-latridou, Introduction au Droit Hellenique, Deventer, 1969; K. D. Kerameus (ed.), Introduction to Greek law, Deventer, 1993; E. Stolfi, Introduzione allo studio dei diritti greci, Turín, 2006.

3 Utilizamos este término en el sentido meramente fáctico de la acción administrativa, pues el término procedimiento implica, según se ha dicho, al menos una mínima sujeción a la ley. 
En la historia de Roma, esta amplitud e indefinición del concepto de tributo es un fenómeno sobrevenido. El tributum republicano estaba minuciosamente regulado por ley, tanto en sus aspectos sustantivos como formales. Fueron las circunstancias y necesidades del imperio las que trajeron a Roma, desde Oriente, otras formas de fiscalidad ajenas a la tradición republicana. La complejidad de las figuras impositivas romanas, tanto en su número como en su naturaleza jurídica, se debe a que las necesidades financieras y, por tanto, tributarias de Roma fueron cambiando a lo largo de su historia, igual que lo hicieron las demás instituciones políticas y sociales.

La creación de nuevos impuestos y la extinción de otros, la adopción de figuras fiscales o parafiscales ajenas al mundo romano procedentes de Oriente, la aparición de nuevos obligados tributarios en las provincias $-\mathrm{y}$, por contra, de amplias bolsas de exención ${ }^{4}$-, su cobertura legal, gestión, recaudación y otras cuestiones de técnica jurídico-impositiva, hace prácticamente imposible establecer una clasificación de los impuestos que responda mínimamente a las categorías existentes en la actual doctrina tributaria. Por otra parte, ni el Derecho romano ni la Jurisprudencia se ocuparon de cuestiones taxonómicas en este ámbito ${ }^{5}$.

Lo que sí observamos, desde finales de la república, es una dicotomía entre aquellos tributos que, en línea con el viejo tributum, recaen sobre los ciudadanos y se atienen a un procedimiento escrupulosamente legal, y aquellos otros, importados o influenciados por los usos tributarios del Oriente helenístico, menos rigurosos en cuanto a sus exigencias legales y procedimentales y que recaen sobre los provinciales. A los primeros podemos englobarlos en una categoría que llamaremos fiscalidad tributaria, por seguir los criterios de rigor procedimental establecidos por el tributum y a los segundos en otra categoría que llamaré fiscalidad post-tributaria. A pesar de esta denominación, no se trata de formas de imposición sucesivas sino superpuestas, pues durante todo el Imperio coexistieron ambas corrientes.

\section{EL TRIBUTUM}

Ya se ha mencionado al tributum como el tributo legal por antonomasia, el tributo perfecto desde un punto de vista jurídico ${ }^{6}$.

4 Las exenciones, aplazamientos, reducciones y condonación de impuestos eran, después del ejército, la segunda partida presupuestaria más importante durante el Alto imperio. Cf. F.M. Heichelheim, Historia Económica y Social de Roma, Madrid, 1982, pp. 126 ss.

5 Nardo E.-Falciani D., «ll sistema tributario dell'antica Roma, prima parte», Rivista della Guardia di Finanza n.2, 1999, p. 6.

6 Ello explica que haya sido objeto de especial atención por los romanistas: Cf. N. D Amati, «Natura e fondamento del tributum romano", Ann. Fac. Giur. Bari, XVI, 1962; V. G. I. Luzzatto, La riscossione dei tributi in Roma e l'ipotesi della proprietà sovrana, Atti del Congreso di Diritto Romano di Verona, 1948; Sobre los impuestos directos en general, pero con especial atención al tributum, cf. L.Neesen, Untersuchungen zu den direkten Staatsabgaben der Römischen Kaiserzeit, Bonn, 1980. 
Hasta la expansión imperial bajo la República, la fiscalidad respondía, en líneas generales, al tipo de fiscalidad cívica propia de las poleis griegas, a lo que Nicolet denomina «finanzas cívicas»?.

Desde el punto de vista tanto político como financiero, el tributum, impuesto directo por excelencia, fue el más importante mientras se mantuvo en vigor. Según Mommsen ${ }^{8}$, sus orígenes se remontan a los tiempos de la monarquía, cuando Servio Tulio lo vinculó al censo, sobre la base del catastro. Sin embargo, hoy se cree que no se introduce hasta principios o mediados del s. IV a.C. ${ }^{9}$

De los libros IV y V de Tito Livio se desprende una clara vinculación entre el tributum y las necesidades militares de Roma. En el asedio de Veyes (406-398 a.C.) las exigencias militares obligaron, por primera vez en la historia de Roma, a mantener un ejército en armas durante varias campañas seguidas, lo que planteó por primera vez la cuestión del sostenimiento de las tropas y la necesidad de establecer un salario para los soldados. El origen del tributum podría estar muy relacionado con estas necesidades militares y, en concreto, con el establecimiento de la soldada. Al ser un impuesto extraordinario ${ }^{10}$, para un fin concreto, al menos en su origen, su validez se limitaba al año en curso. Por eso, ciertos años se pudo suspender, como ocurrió en 347/5 a.C. ${ }^{11}$

Después de la victoria de Paulo Emilio sobre Macedonia el 167 a.C., la afluencia de riquezas de las provincias orientales hizo innecesario el tributum ${ }^{12}$, que sin llegar a ser formalmente abolido, cayó en desuso y sólo se restableció bajo el consulado de Hirtius y Pansa el 43 a.C., no sabemos si de manera transitoria o definitiva $^{13}$. Por eso, no es que el impuesto fuera suprimido el 167 a.C, como a veces se ha afirmado, sino que no hubo necesidad de volver a decretarlo. En cualquier caso, el tributum no está documentado en época imperial ${ }^{14}$.

Su aprobación y gestión anual estaban sometidas a riguroso procedimiento legal, como no podía ser de otra manera en el ámbito de la civitas: el tributum debía ser decretado por el Senado, titular exclusivo del ius imponendi y podía, al menos en teoría, ser impugnado por el tribuno de la plebe.

7 C. Nicolet, Roma y la conquista del mundo mediterráneo. Vol. 1, Las estructuras de la Italia romana, Barcelona, 1982, p. 156. Sobre las finanzas en la Antigüedad, cf. G. Di Renzo, La Finanza Antica, Nápoles,1955; M. Finley, The Ancient Economy, Berkeley, 1999. Sobre las finanzas en Roma, cf. L. Clerici, Economia e finanza dei Romani, Bolonia, 1934; F. De Martino, Historia económica de la antigua Roma, Madrid, 1979; Íbid., Nuovi studi di economia e diritto romano, Roma, 1988; Sobre las finanzas y la fiscalidad de las ciudades griegas en general, cf. A. Andreades, A history of Greek Public Finances, Cambridge, Mass, 1933; M. Rostovtzeff, Historia Social y Económica del Mundo Helenístico, 2 vols., Madrid, 1967; E. Cavaignac, Population et Capital dans le monde mèditerranéen antique, París, 1923.

8 T.Mommsen, Historia de Roma, vol. I, Madrid, 2003, p. 114. p. 100.

9 C. Nicolet, Tributum. Recherches sur la Fiscalité Directe sous la Republique Romaine, Bonn, 1976,

${ }_{10}$ Con el tiempo se fue transformando progresivamente en un impuesto ordinario. Cf. V. G. I. Luzzatto, Op. cit., p. 215.

11 Tito Livio, VII, 27, 5.

12 Plinio, XXXIII, 56; Cicerón, De Off., II, 76.

13 Plutarco, Emilio Paulo, 38.

14 E. Nardo y D. Falciani, Op. Cit., p.7 
Cabría considerar que el tributum no era en realidad un impuesto, que su relación con la civitas no era de derecho público sino privado, pues se trataría, más que de un tributo propiamente dicho, de una especie de empréstito o aportación de capital como la que pueden hacer los socios de una sociedad mercantil a favor de la propia sociedad, y que por tanto sería reembolsable. Eso fue lo que ocurrió el 187 a. C., cuando el botín obtenido de los gálatas permitió reembolsar una parte del tributum pagado en los años precedentes ${ }^{15}$.

Los contribuyentes sujetos al tributum son exactamente los mismos que están sujetos al servicio militar: los ciudadanos varones adultos que pudiesen portar armas. Sin embargo, los ciudadanos que iban a ser de hecho movilizados no pagaban el tributum. Se trataba de prestaciones alternativas e incompatibles: o bien se pagaba el tributum, o bien se recibía la soldada. Los immunes militiae y los individuos que no son sui iuris ${ }^{16}$ (mujeres, viudas, huérfanos), no están sujetos al tributum, pero sí a otra contribución parecida que se destinaba a la adquisición y mantenimiento de los caballos necesarios para la guerra ${ }^{17}$.

Como era propio de una polis, los ricos servían en el ejército más a menudo y contribuían más. Pero además de la riqueza había otros criterios de sujeción al tributum que quedaban al arbitrio del censor: el origen familiar, el desempeño de ciertas funciones, encarnar determinados valores morales, etc. ${ }^{18}$

Conforme a los cánones de la fiscalidad cívica griega, el tributum refleja la ideología del soldado-ciudadano que, basado en la igualdad proporcional, intenta equilibrar los derechos y los deberes, las cargas y las ventajas de ricos y pobres.

Se suele decir que la cuota tributaria era del 1 por 1000 del census, aunque también podía ser del 2 o 3 por 1000 (tributum simplex, duplex o triplex) ${ }^{19}$. Lo cierto es que no sabemos cuál era la cuota en los siglos III y II a.C. ni si existía un tipo impositivo normal, regular, cada año.

Desde 167 a. C. el impuesto desaparecerá y un siglo más tarde desaparecerá también la obligación para todos los ciudadanos de servir en el ejército.

\section{LA FISCALIDAD TRIBUTARIA}

Desaparecido el tributum y para mantener un ejército permanente cada vez menos cívico, los ciudadanos tuvieron que aceptar, desde comienzos del principado, la creación de nuevas figuras impositivas. Entre las reformas fiscales que realizó Augusto, destaca la creación de dos nuevos tributos: La vicesima hereditatum y la capitatio terrena. Desde la introducción de estos nuevos tributos, Roma pasa

\footnotetext{
15 Tito Livio, XXXIX, 7, 1-2.

16 Es decir, paterfamilias.

17 C. Nicolet, Op. Cit. 1, p. 164

18 C. Nicolet, Op. Cit. 2, p. 29.

19 E. Nardo y D. Falciani, Op. Cit., p.7.
} 
de tener una fiscalidad de tipo cívico a otra de tipo «monárquico»20: el tributum entendido como contribución extraordinaria que debía ser consentida en cada indictio expresamente por el Senado, es sustituido por impuestos ordinarios consensuados en un único acto, el de su instauración. No obstante, y a pesar de su carácter permanente y su origen oriental, los nuevos tributos augusteos conservan todo el rigor procedimental del viejo tributum, como corresponde a impuestos que sólo recaían sobre ciudadanos romanos. Por ello los hemos englobado dentro de lo que llamo «fiscalidad tributaria».

\subsection{La vicésima hereditatum}

Fue un impuesto de sucesiones, establecido el 6 a.C. mediante la Lex Iulia vicesima hereditatum et legatorum ${ }^{21}$.

En el 40 a. C. fracasó un primer intento de implantación de este impuesto, al parecer de origen tolemaico, por la fuerte oposición del Senado ${ }^{22}$. Pero después de su victoria en la guerra civil, Augusto logró imponerlo, aunque no sin dificultad, por carecer de precedentes en el Derecho romano. No obstante, y a pesar de su origen foráneo, la vicesima tuvo un desarrollo normativo acorde con los principios iuscivilistas.

Se trataba de un impuesto sobre las sucesiones mortis causa cuya cuota era del cinco por ciento del caudal hereditario. Sólo gravaba a los ciudadanos romanos y parece ser que los parientes más próximos y los pobres estaban exentos ${ }^{23}$. Las normas de ejecución del impuesto emanaban de la Lex Papia Poppaea, que conocemos por los comentarios de los jurisconsultos ${ }^{24}$. Establecía, entre otros extremos, que en caso de muerte del heredero o del legatario cuando el testador aún vivía y después de haber sido otorgado el testamento, éste debía considerarse caducado y la cuota del impuesto debía ser devuelta al erario público.

Lo mismo ocurría en caso de muerte o pérdida de derechos civiles por parte del heredero o legatario después de la muerte del testador, pero antes de la apertura del testamento. Es decir, que el Estado no sólo percibía como norma general la vicesima de las herencias y legados, sino que en ciertos supuestos legales se apropiaba de la totalidad de la herencia.

La elevada recaudación de este impuesto explicaría, según la teoría tradicional ${ }^{25}$, la extensión del derecho de ciudadanía a todos los peregrinos del Imperio por el emperador Caracalla, quien además duplicó el tipo impositivo. En 212 ya había

20 C. Nicolet, Op. Cit. 2, p. 98.

21 Una buena síntesis sobre los aspectos más polémicos de este tributo en L. Rodríguez Álvarez, «Notas en torno a la Lex lulia de vicésima hereditatium», Memorias de Historia Antigua, III, Oviedo, 1979, pp. 199-215.

22 Apiano, Bell. Civ., V, 67

23 L. Rodríguez Álvarez, Íbid. p. 207.

24 Gayo, Inst., 178; Ulpiano, Fragm. XI, 20.

25 Dion Casio, Historia Romana, 77, 9, 4. 
por todo el imperio muchos ciudadanos; además, los nuevos ciudadanos conservaron el uso de los derechos indígenas en sus ciudades (así los judíos y los egipcios) al mismo tiempo que permanecían sometidos al conjunto de sus obligaciones fiscales, comprendidas aquellas de las que estaban exentos los ciudadanos romanos (la iaographía en Egipto, por ejemplo ${ }^{26}$ ).

\subsection{La capitatio terrena}

Aunque Italia estaba en principio exenta del stipendium que tributaban las provincias, Augusto creó la capitatio terrena como un impuesto equivalente que comenzó a aplicarse en Italia y paulatinamente se fue extendiendo al resto del Imperio. Se trataba de un impuesto que gravaba la tierra con independencia del estatuto legal y personal del propietario, por lo que se trataba de un impuesto real. Por eso no se vio afectado por la constitutio antoniniana que universalizó la ciudadanía romana a todo el territorio del Imperio ${ }^{27}$.

La capitatio terrena, como el viejo tributum y la vicesima, era un tributo rigurosamente reglado. Igual que el tributum, tenía como base el catastro, ahora extendido a todo el Imperio. Este catastro imperial fue un inmenso proyecto de Augusto que tardó treinta años en completarse y que permitió la recaudación de la capitatio en todo el Imperio. La monumental obra fue colocada en el pórtico de Octavia. Al mismo tiempo, Augusto llevó a cabo el censo de habitantes, con indicación de sus propiedades muebles e inmuebles, animales, esclavos y colonos.

El catastro dividió toda la tierra del Imperio en unidades llamadas caput, cada una de las cuales era gravada con una imposición llamada capitatio. El catastro servía para determinar la base imponible de cada sujeto pasivo, cuya cuota era fijada cada año por un edicto imperial. Se consideraba como hecho imponible la simple posesión de la tierra.

El censo y el catastro permitieron superar el principio de responsabilidad colectiva que predominó durante la República y sustituirlo por el principio de responsabilidad individual ante la hacienda pública ${ }^{28}$. No obstante, es posible que en determinadas zonas poco romanizadas el censo se limitase a evaluar la capacidad contributiva global del territorio o de la población, en lugar de hacerlo individualmente para cada contribuyente ${ }^{29}$. Esta responsabilidad individual se aplicaba sólo

26 M. Sartre, El Oriente Romano. Provincias y Sociedades provinciales del Mediterráneo oriental, de Augusto a los Severos (31 a.C.-235 d.C.), 1994, p. 91.

27 Sobre las implicaciones fiscales de la Constitutio Antoniniana, Vid. R. Fernández González, «Casio Dion y los motivos (¿fiscales?) de la concesión (¿universal?) de la ciudadanía romana», en Koinós Logos. Homenaje al profesor José García López, E. Calderón, A. Morales, M. Valverde (eds.), Murcia, 2006, pp. 381-395.

28 En efecto, el tributum era un impuesto de cuota: se fijaba de antemano la cantidad total a recaudar y después se fijaba por reparto la cantidad que cada ciudadano debía aportar.

${ }^{29}$ López Barja en P. Fernández Uriel, «Un fundamento en la Economía de los Estados modernos: EI Sistema Tributario romano». Segundo coloquio de la AIER. La aportación romana a la formación de Europa: Naciones, lenguas y culturas, Madrid, 2005, pp.43-54, nota. 
a las provincias imperiales y, en cualquier caso, la comunidad afectada se responsabilizaba de la recaudación.

Para mantener al día el catastro, era obligatorio declarar cualquier transmisión de la propiedad o de la posesión de la tierra. Si en el curso del período impositivo, llamado indictio, se producía una disminución apreciable de las rentas agrarias, el contribuyente podía solicitar una reducción del impuesto al censitor. Inversamente, si aumentaba el valor de la tierra se podía aumentar de oficio la cuota del impuesto.

\section{RASGOS DE LA FISCALIDAD POST-TRIBUTARIA}

Como ya se ha mencionado, a partir de la expansión imperial de la República se introducen en Roma figuras fiscales y parafiscales, generalmente de origen exótico, que se alojan como cuerpos extraños en una fiscalidad conformada según el paradigma tradicional del tributum. Figuras anómalas, podría decirse, en tanto que carentes de la pureza procedimental, el rigor jurídico y la racionalidad de la fiscalidad tributaria: tributos sin hecho imponible, sin cuota asignada, sin sujeto pasivo determinado o determinable, sin período de devengo, confiscatorios o punitivos, etc.

Es evidente que esta deriva responde a las nuevas necesidades financieras de una Roma en expansión y obedece a la misma lógica por la que las instituciones políticas de la República dan paso a las del Imperio. Pero al igual que las instituciones imperiales no hicieron desaparecer sin más a las de la República, los nuevos modelos fiscales no desplazaron a los antiguos, sino que coexistieron con ellos creando un sistema dual.

Podemos distinguir en el ámbito de la fiscalidad post-tributaria una serie de rasgos anómalos que pueden presentarse, con más o menos nitidez, aislados o combinados entre sí. Algunos de estos rasgos, aisladamente considerados, son propios de la pura y simple confiscación. Otros rasgos pueden darse también en los tributos más rigurosamente legales. Lo cierto es que entre el tributum republicano y el terrorismo fiscal de los años de las guerras civiles, especialmente entre el 49 y el 31 a. C., hay un continuum en el que es difícil señalar dónde termina lo que hoy llamaríamos la legalidad de un tributo.

Sin pretender ser exhaustivos, podemos mencionar entre los rasgos de este tipo de tributos los siguientes:

1) Se crean ex profeso para satisfacer determinados fines no previstos por una norma general.

Están, por tanto, afectos a la satisfacción de una necesidad determinada y, a menudo, sobrevenida. Es el caso, por ejemplo, de las confiscaciones de guerra o de la obligación de alojar y alimentar a los soldados por parte de la población civil. Algunas modalidades de liturgia son también contribuciones ad hoc impuestas para 
satisfacer necesidades públicas inmediatas. Se trata sobre todo de prestaciones personales, tales como la angareia o las derivadas del sostenimiento del cursus publicus, que mencionaremos más adelante.

Dado el carácter excepcional de este tipo de contribuciones, y al no derivar de una norma legal establecida, suelen adolecer también de otros defectos formales, como la indeterminación del sujeto pasivo y de la cuota tributaria. Se trata, realmente, de una vía de hecho que emplea el Estado para satisfacer una necesidad concreta que se agota en sí misma. Esta finalidad pública, justificada en el bien general, es lo único que nos permite considerar este tipo de contribuciones como tributos y mantenerlas, aunque en sus mismos límites, dentro de lo jurídico.

2) Aunque su naturaleza es esencialmente recaudatoria, pueden tener una finalidad extratributaria.

Por ejemplo, una finalidad punitiva. Es lo que sucede con la confiscación de bienes en las proscripciones de las guerras civiles. Lo mismo sucede con los ingresos públicos procedentes de multas o sanciones.

Sin embargo, algunos tributos rigurosamente legales también pueden contener un carácter punitivo. Así, la Lex lulia de vicesima hereditatum et legatorum contemplaba que en caso de sucesión legítima la cuota del impuesto era mucho menor que en la sucesión testamentaria, en cuyo caso era casi confiscatoria. La causa, según Di Renzo, era la defensa de los valores familiares por parte de Augusto frente a la tendencia creciente en la época a testar a favor de libertos y cortesanas ${ }^{30}$.

Más lejos llegan aún los supuestos de incapacidad sucesoria contemplados por la Lex Iulia de maritandinis ordinibus. Mediante esta ley, Augusto sancionó con la incapacidad para adquirir bienes mortis causa a los solteros y los casados sin hijos -éstos sólo en media parte-. Dichos bienes pasaban a los herederos y legatarios que fueran patres y, en defecto de estos, se consideraban bona caduca ${ }^{31}$ y pasaban al aerarium (al fiscus, a partir de Caracalla ${ }^{32}$ ). El sentido de esta ley era, como en el caso de la Lex lulia de vicesima hereditatum et legatorum, la defensa de los valores familiares por parte del Estado. Es decir, que el Estado no sólo percibía como norma general la vicesima de las herencias y legados, sino que en ciertos supuestos legales se apropiaba de una parte o de la totalidad del caudal hereditario.

Por otra parte, el alto Imperio desconoció la virtualidad de los impuestos como instrumento de la política económica, tal como ocurre hoy en día, y difícilmente eran posibles un plan financiero, una política fiscal y una política económica a través de los impuestos $^{33}$. Diocleciano, sin embargo, utilizó al parecer conscientemente el tributum soli

30 G. Di Renzo, La Finanza Antica, Nápoles,1955, p. 196.

31 Los bona caduca eran bienes cuya transmisión o adquisición era legalmente nula.

32 Ulpiano, 17, 2.

33 L.Neesen, Op. cit., p. 170. 
y el tributum capitis para la dirección y reglamentación de la economía, a favor de la población urbana o de la recuperación económica de las provincias devastadas, o para intensificar o relajar la vinculación de los campesinos a la tierra. ${ }^{34}$

3) No tienen un origen legal, o su regulación legal es deficiente.

Frecuentemente, además, tienen un origen consuetudinario ajeno a la tradición jurídica romana. Es el caso, entre otros, del aurum coronarium, al que nos referiremos más adelante, de las liturgias o de las cláusulas penales en los contratos privados.

Sin entrar en una cuestión tan compleja como la de la naturaleza de la ley, hemos de interpretar esta expresión en el contexto del Derecho romano, es decir, en su sentido lato: Según el Digesto, es ley «el precepto común, el dictado de personas prudentes, la represión de los delitos que se cometen voluntariamente o por ignorancia, el convenio de la república»35.

Pero también «lo que plugo al príncipe tiene fuerza de ley: así es, en efecto, dado que por la ley regia, que se promulgó acerca del imperio del príncipe, el pueblo le confiere todo su imperio y potestad» 36 .

En otras palabras, es ley tanto la voluntad popular emanada del Senado como la voluntad emanada del Príncipe. En este sentido, nada nos permite considerar más legítimo el tributum de la época republicana que los impuestos de la época imperial. Sin embargo, esto no quiere decir que todo carga contributiva impuesta por el Estado sea igualmente legítima. Hay distintos niveles de legalidad o legitimidad, que dependerá en buena medida de la pureza del procedimiento.

Un ejemplo de defecto de procedimiento lo encontramos en los arbitrarios tributos que impuso Calígula sobre los comestibles, la prostitución, los mozos de carga, los litigios y el matrimonio ${ }^{37}$. Refiere Suetonio cómo todos estos impuestos, aunque se habían anunciado, no habían sido publicados. Ello dificultaba su cumplimiento por lo que, a instancias del pueblo, se procedió a fijar en público la nueva normativa. Pero Calígula la hizo escribir en caracteres tan pequeños y se expuso en un lugar tan inaccesible, que no se pudieron sacar copias ${ }^{38}$. Es interesante observar que, antes que la supresión de impuestos tan arbitrarios, lo que se reclamaba era que se cumpliera con el trámite legal de su publicación. Es el mismo prurito por la pureza del procedimiento que hemos visto en la interpretación que hace Suetonio de la rebelión de Boudicca.

4) Existe confusión entre el sujeto activo y el sujeto pasivo.

En ciertos casos, la obligación tributaria puede no estar impuesta por el Estado, sino por el propio sujeto pasivo, como es el caso de la adiectio, la ampliatio y la

34 F.M. Heichelheim, Op. cit, p. 180.

35 Digesto, 1, 3, 1.

36 Idem, 1, 4, 1

37 Suetonio, Calígula, 40.

38 Idem, 41. 
pollicitatio ${ }^{39}$, figuras impositivas muy relacionadas entre sí, o de las multas a favor del fisco acordadas por las partes en contratos privados.

La summa legitima o summa honoraria es un tipo de ingreso fiscal relacionado especialmente con la administración municipal. En su origen es la contribución, legalmente estipulada, que los magistrados elegidos habían de hacer a favor de la ciudad, y que normalmente se empleaban en financiar juegos, aunque también se podían destinar a la construcción de edificios públicos o, incluso, no destinarse a ningún fin concreto.

La verdadera naturaleza jurídica de la summa legitima es difícil de precisar. Por un lado, estamos ante una obligación legal, cuya cuantía estaba perfectamente determinada y dependía de cada ciudad y del rango de la magistratura en cuestión. Su parentesco con las liturgias y con otras formas de munificencia voluntaria es evidente.

Pero lo realmente interesante de este tributo es que, con frecuencia, los obligados a pagar la summa legitima incrementaban voluntariamente la cantidad que debían pagar, incremento que se conocía como adiectio o ampliatio.

No cabe duda de que un impuesto en el que, con frecuencia, se paga una suma superior a la que el contribuyente está legalmente obligado, es un impuesto que escapa a la lógica del tributo entendido en sentido estricto.

El fenómeno de la adiectio se puede explicar como una consecuencia de la prosperidad económica y del afán de emulación y de competencia propio de las nuevas élites urbanas durante el alto Imperio ${ }^{40}$.

Pero cabe también entender este tipo de contribución como una reminiscencia del evergetismo propio de las finanzas cívicas de la polis antigua, en la que, como hemos visto, se da una cierta identidad entre el sujeto activo y el sujeto pasivo de los tributos ${ }^{41}$.

Existe, por último, una figura afín a la summa legitima y a la adiectio: la pollicitatio, sobre la que existe una jurisprudencia relativamente abundante. La pollicitatio es la promesa que hace el candidato a una magistratura o cargo municipal de realizar un acto de liberalidad para con su ciudad -como sufragar unos juegos o edificar un templo- en caso de resultar elegido.

La pollicitatio podría ser, en su origen, una adiectio aplazada o sometida a una condición suspensiva. Al poder decidir el propio obligado el momento del cumplimiento de su promesa, existía un mayor margen de maniobra para hacer frente al pago, lo que permitió que un grupo algo más amplio —o menos rico- de ciudadanos accedieran a las magistraturas urbanas. La pollicitatio bien podía, a su vez, ser incrementada en el momento de su cumplimiento por encima de la canti-

39 P. Garnsey, «Taxatio and Pollicitatio in Roman Africa», Journal of Roman Studies, 61, 1971.

40 P. Garnsey, Op. Cit. p.117.

41 Sobre el evergetismo en el mundo antiguo en general, cf. A. R. Hands, Charities and social aid in Greece and Rome, Cambridge, 1968. 
dad prometida. Aunque se trata de una promesa hecha voluntariamente y cuya cuantía, por tanto, la fijaba el propio candidato, llegó a ser moral y legalmente obligatoria en tiempos de los Antoninos y de los Severos ${ }^{42}$.

El hecho de tratarse de una obligación autoimpuesta no hace perder a la pollicitatio su carácter de obligación, incluso transmisible a los herederos ${ }^{43}$, aunque sí, en nuestra opinión, su naturaleza tributaria en sentido estricto. En efecto, no existe el elemento subjetivo de un poder público titular del ius imponendi: es el propio sujeto pasivo la fuente de la obligación ${ }^{44}$.

\section{5) El sujeto pasivo no está bien determinado.}

En algunas obligaciones tributarias, como las liturgias, el incumplimiento por parte del contribuyente traslada la obligación a otros sujetos pasivos -el propio recaudador, los ciudadanos más ricos, etc.- ajenos al hecho imponible. Su justificación última radica en la prevalencia de las necesidades del Estado sobre los derechos del individuo.

Toda comunidad antigua exigía a cada uno de sus miembros el sacrificio de sus intereses individuales a los de la colectividad. Las monarquías orientales aplicaron desde siempre este principio, que después pasó al mundo helenístico y, de éste, a Roma. Podría deducirse de esto que el fundamento jurídico de las liturgias es similar al del tributum. Rostovtzeff sostiene que la esencia de las liturgias se aviene incluso mejor con el espíritu de la polis que con el de los imperios orientales $^{45}$. Sin embargo, recuérdese que, mientras las liturgias son una carga impuesta, el tributum era una contribución consentida.

El sistema de liturgias o cargas públicas implicaba la prestación patrimonial y personal y hacía responsables a las clases privilegiadas y ricas de las obligaciones de los pobres.

Aunque el origen del sistema parece ser Egipto, cada vez fue empleado en mayor escala en todo el Imperio y ya en el siglo II d. C. estaba en pleno florecimiento.

Un interesante ejemplo de este tipo de prestación, en este caso personal, lo constituye la angareia, que consistía en la obligación de suministrar animales de carga, arrieros o barcos para el transporte de tropas o enseres del Estado. Los Evangelios nos describen con un ejemplo cómo se exigía esta contribución ${ }^{46}$ : Simón Cireneo, obligado a cargar con la cruz de Cristo camino del Calvario, fue sometido a una angareia. A partir de su origen, probablemente sirio, los romanos extendieron la angareia a todo el Imperio y trataron de reglamentarla, pero sin éxito,

42 Sobre la obligatoriedad moral, cf. P. Garnsey, Op. Cit., p. 116. Sobre su regulación legal, todo el título 12 del Libro 50 del Digesto está dedicado a esta institución.

43 Digesto, 50; 12; 2, 6, 9, 10,14.

44 Sólo si la promesa se hizo sin justa causa, carece de fuerza obligatoria, a menos que ya hubiera empezado a cumplirse. Cf. Digesto, 50,12, 1.

45 Op. Cit. 2, p. 212.

46 Lucas, 23, 26; Marcos, 15, 21. 
pues su carácter confiscatorio y arbitrario sólo permitía o suprimirla o mantenerla. Claudio, consciente de los efectos nefastos de esta liturgia, intentó mitigarla mediante un edicto ${ }^{47}$. Sin embargo, Calígula la aplicó en la propia Roma para transportar el mobiliario de la corte, confiscando todos los carruajes de alquiler y los caballos de los molineros, hasta el punto de que la capital quedó desabastecida de harina ${ }^{48}$.

La angareia ilustra muy bien la incapacidad de los romanos para regular una práctica fiscal abiertamente arbitraria, para traducir en términos legales un concepto completamente extraño a la rigurosa conciencia jurídica romana.

Lo mismo cabe decir de las prestaciones obligatorias de víveres y alojamiento para el ejército, que a veces adoptaban la forma de ventas forzosas, pero que en realidad eran auténticas requisas.

Otro ejemplo de liturgia se refiere al envío de correspondencia oficial y el transporte de funcionarios imperiales. Para ello se estableció el cursus publicus, algo bastante parecido a un servicio postal público, pero que necesitó igualmente del concurso del trabajo coercitivo para su sostenimiento.

Ya hemos mencionado que la idea de la liturgia no es del todo ajena al ideal cívico de la ciudad-Estado. Es cierto que cualquier contribución directa es aceptada sólo en la medida en que sea absolutamente necesaria y tenga carácter extraordinario. Sin embargo, estaba muy arraigada la idea de que los ciudadanos ricos debían contribuir al bienestar colectivo en momentos de urgente necesidad. Mientras la carga no fue excesiva, fue más o menos aceptada por las oligarquías urbanas. Pero a partir de fines del siglo I d. C., cada vez fue más difícil hallar personas dispuestas a aceptar servir a la comunidad sin más compensación que el reconocimiento de sus conciudadanos.

6) Inexistencia de hecho imponible atribuible al sujeto pasivo.

En ocasiones, el contribuyente no realiza ninguna conducta que suponga una manifestación de riqueza. Por ejemplo, el mencionado aurum coronarium se define, en su origen, por gravar la obtención de un triunfo militar de quien ha de percibir el tributo ${ }^{49}$. La determinación del sujeto pasivo no guarda relación alguna con el hecho imponible.

47 C.I.L., III, 7251.

48 Suetonio, Caligula, 39.

49 Sobre el Aurum Coronarium, cf. C. Lacombrade, «Notes sur I Aurum Coronarium», Revue des Ėtudes Anciennes, 51/1-2, 1949, p. 54-59; W. Schubart, «Zum Edikt über das Aurum Coronarium», Archiv für Papyrusforschung und verbandte Gebiete, 14, 1941, pp. 44-59; A. K. Bowman, «The crown-tax in Roman Egypt», BASP, 4, 1967, pp.59-74. T. Klauser, «Aurum Coronarium», Reallexikon für Antike und Christentum, 1, 1959, pp. 1010-1020; M. Rostovtzeff, Historia Económica y Social del Imperio Romano, vol. II, Madrid, 1967; C. Ando, Imperial ideology and provincial loyalty in the Roman empire, Berkeley, 2000, pp. 175 ss; La principal fuente legislativa sobre este tributo es el Código Teodosiano, 12, 13.1-13.6. 
Cuando un general había obtenido una victoria en una provincia romana, era costumbre que las ciudades de esa provincia le enviaran coronas de oro, que eran exhibidas en triunfo en Roma ${ }^{50}$.

La práctica parece tener un origen helenístico. Tras la conquista de Persia se enviaron coronas a Alejandro que pesaron 10.500 talentos. En el triunfo ofrecido a Cneo Manlio tras la victoria sobre los galos en Asia se exhibieron doscientas coronas $^{51}$. En tiempos de Cicerón, parece que la costumbre fue sustituida por la entrega de dinero 52

Este pago, que en un principio era voluntario, se llegó a considerar algo así como un tributo que, en ocasiones, parece haber sido exigido por gobernadores aún sin haber obtenido ninguna victoria. Julio César hizo aprobar una ley que prohibía exigir el aurum coronarium a menos que se hubiera decretado un triunfo ${ }^{53}$. Durante el Imperio se exigió con ocasión de otros acontecimientos, como en la adopción de Antonino Pío ${ }^{54}$.

Con el tiempo, el aurum coronarium llegó a constituir un verdadero impuesto extraordinario y se convirtió en un impuesto corriente desde el Siglo II d. C. Adriano declaró a Italia exenta del impuesto y redujo su cuantía para el resto de las provincias ${ }^{55}$. Caracalla, en cambio, lo incrementó ${ }^{56}$, mientras que Alejandro Severo perdonó después del 222 todas las cantidades que adeudaban por este concepto las ciudades del Imperio ${ }^{57}$.

Gracias a documentos egipcios sabemos que se recaudaba dinero para este impuesto y que este dinero era independiente del que se recaudaba para las ofrendas de coronas de oro extraordinarias, normalmente con motivo del acceso al trono, o de alguna gran victoria o acontecimiento notable. Valeriano recibió coronas de oro pero no es seguro que en su época pudiera recaudarse el impuesto, que no obstante reaparece después, permaneciendo en vigor aún en el siglo IV ${ }^{58}$.

7) La cuota tributaria, el período de devengo u otros elementos esenciales son indeterminados y quedan al arbitrio del recaudador o de la autoridad.

Es el caso, por ejemplo, de las requisas y confiscaciones, así como de ciertas liturgias, en especial las consistentes en prestaciones de tipo personal. Se trata probablemente de las circunstancias más antijurídicas que podemos encontrar en las obligaciones tributarias, porque se destruyen por completo los principios de seguridad jurídica, proporcionalidad, capacidad económica y no confiscatoriedad.

50 Tito Livio, XXXVIII, 37; XXXIX, 7.

51 Tito Livio, XXXIX, 7.

52 Cicerón, De Lege Agraria, II, 22.

53 Ídem, In Pisonem Oratio, 37.

54 S. H. A., Antonino Pio, 4.

55 M. Rostovtzeff, Op. cit. 2, p. 186.

56 Dion Casio, Historia Romana, LXXVIII, 9.

57 J.P. Coriat, Le Prince Legislateur, Roma, 1997, p. 479.

58 Cod.lus., 10, 74. 
Hay que tener en cuenta que, mientras que los impuestos ordinarios tienen un vencimiento y una cuota que se conocían de antemano, nadie puede prever la llegada de un funcionario imperial o municipal que requisa animales o alimentos para el ejército o que establece en sus casas alojamiento para los oficiales.

Muchos impuestos tenían fijado en el sistema fiscal romano un período de devengo, y sabemos de la existencia de plazos estrictos para cumplir con las obligaciones tributarias, transcurridos los cuales se abría sin más la vía de apremio, aunque también cabía solicitar al juez una moratoria, con plazos también estrictamente tasados ${ }^{59}$. Pero en otras ocasiones se pasaban por alto estos requisitos. Es lo que ocurrió, por ejemplo, cuando Marco Antonio exigió el pago en dos años de los tributos correspondientes a diez ${ }^{60}$.

\section{8) Derivan de relaciones de derecho privado o de derecho penal.}

Los bona vacantia, los bona caduca y los mencionados supuestos relativos a legados y herencias establecidos por Augusto, son ejemplos de contribuciones no sólo con una fuerte finalidad extratributaria, según hemos visto, sino también con una naturaleza jurídica más civil que fiscal.

Los bona caduca son los bienes precedentes de legados y herencias que, por diferentes supuestos de incapacidad sucesoria de los herederos o legatarios, o por indignitas, pasaban a disposición del aerarium o del fiscus ${ }^{61}$.

Una intervención arbitraria del fisco en los derechos sucesorios es la norma que estableció Nerón, según la cuál los bienes de los que se hubiesen mostrado en su testamento ingratos con el príncipe pasaban a ser propiedad del fisco ${ }^{62}$.

Una figura afín eran los bona vacantia, bienes que pasaban al fisco ante la inexistencia de herederos o al rechazar éstos la herencia.

Un curioso ejemplo de tributo o tasa judicial es el que impuso Calígula a los litigantes en procesos civiles, consistente en la cuadragésima parte de la cantidad en litigio. Para evitar fraude en el cumplimiento de este tributo, se establecieron penas contra los litigantes que hubieran transigido o desistido de sus pretensiones $^{63}$.

59 En Digesto, 49, 14, 45, se establecen moratorias de dos o tres meses, según la cuantía de la deuda tributaria. Sin embargo, un papiro del reinado de Cómodo, recogiendo una carta dirigida por el prefecto de Egipto a los strategoi de Tebaida, Hepta Nomoi y Arsinoe, establece que se vendan los bienes embargados por deudas fiscales si estas no eran pagadas en el plazo de seis meses: Cf. F. Millar, «The Fiscus in the First Two Centuries», Journal of Roman Studies, 53, 1 y 2, 1963, p. 32.

60 Apiano, Guerras Civiles, V, 5.

61 Digesto, 34, 9. Sobre las relaciones entre aerarium y fiscus, cf. C.H.V. Sutherland, «Aerarium and Fiscus during the Early Empire», American Journal of Philology, 66, № 2, 1945; A.H.M. Jones, «The Aerarium and the Fiscus», Journal of Roman Studies, 40, 1950; F. Millar, Op. Cit.; T. Frank, «Augustus and the Aerarium», Journal of Roman Studies, XXIII, 1933.

62 Suetonio, Nerón, 32.

63 Ibid., Calígula, 40. 
Parece ser de origen tolemaico la norma de que pasen a ser propiedad del emperador los bienes de las personas condenadas en procesos penales - los bona damnatorum - especialmente por el delito de maiestas.

El Digesto establece que se confisquen los bienes de los condenados cuando lo son «a pena de pérdida de la vida o de la ciudadanía, o cuando se les castiga con la esclavitud „64. También en este caso es difícil precisar cómo semejante costumbre se incorporó al Derecho romano.

El primer caso claro que conocemos en Roma data del reinado de Tiberio, y es el de C. Silio, condenado el 24 d. $C^{65}$. Pero hay dos precedentes de época de Augusto: en 26 a. C., cuando el Senado votó la confiscación a favor de Augusto de los bienes de Cornelio Galo y en 6 d. C., cuando sucedió lo propio con los bienes de Arquelao de Judea ${ }^{66}$.

Un rescripto de Adriano establece la diferencia entre los objetos personales del reo de muerte, los llamados por el Digesto «trapos», que pasan a ser propiedad de los soldados encargados de la ejecución, y los bienes u objetos de valor que estén en posesión del reo ${ }^{67}$. Si el valor de tales pertenencias no excede de cinco áureos, pasan a manos de aquellos. Si exceden de dicha suma, "deben reservarse para lo que se suele gastar en el oficio de los gobernadores, como el fondo para escritorio que se atribuye a algunos oficiales, o para gratificar servicios de militares, o para subvencionar a los indígenas que hayan acudido en embajada o por otro motivo.» En otras palabras, deben pasar al fiscus del gobernador de la provincia.

Sin embargo, a pesar de su carácter confiscatorio y, por tanto, antijurídico, se solía respetar el derecho de los herederos del condenado a una parte de los bienes de éste ${ }^{68}$. Por otra parte, un rescripto de Septimio Severo y de Caracalla impedía al procurador imperial vender bienes mientras fueran objeto de litigio; por tanto, los bona damnatorum de un reo de un delito de lesa majestad que hubiera fallecido, no podían ser vendidos por el fisco si el heredero del reo iniciaba acciones legales para probar su inocencia.

Las multas por infracciones menores, y cuyo importe ingresaba en el fisco, están atestiguadas por una numerosa jurisprudencia ${ }^{69}$.

Pero existía, además, un tipo de multas cuyo beneficiario era el fiscus aunque tenían su origen en el incumplimiento de obligaciones de derecho privado ${ }^{70}$. Se trata de cláusulas penales mediante las que las partes se obligan a pagar al fisco en

64 Digesto. 48, 20, 1.

65 Tácito, Anales, 4, 20.

66 Le Gall, J. y Le Glay, M. El Alto Imperio, desde la batalla de Actium hasta la muerte de Severo Alejandro, Tres Cantos, 1995, p. 98.

67 Digesto, 48, 20, 6.

${ }^{6} / d e m, 48,20,7$. Incluso hay precedentes de renuncia del fisco a la percepción de estos bienes, como hizo Adriano respecto de los hijos de Albino, aduciendo que prefería "ampliar su imperio con el aumento de hombres que a fuerza de dinero».

69 Idem, 47.12. 3. 5 .

70 Idem., 49. 14. 1; 4. 8. 42. 
caso de incumplimiento, y que son compatibles con la obligación de indemnizar a la parte perjudicada por el mismo. La base legal de esta institución en el Derecho romano no está clara, aunque sí su origen, que como en los casos anteriores, está en el Egipto tolemaico.

\section{CONCLUSIONES}

Con el tránsito de la República al Imperio, el sistema impositivo romano experimenta una profunda transformación. La fiscalidad cívica regulada minuciosamente en el tributum tiene su continuidad en las reformas fiscales emprendidas por Augusto, principalmente en el nuevo impuesto de sucesiones, la vicesima hereditatum, que sólo gravaba a los ciudadanos romanos, y en la capitatio terrena, impuesto real que no iba vinculado al status civitatis. Concebidos en su origen como tributos ciudadanos, terminaron por imponerse en todo el Imperio: la capitatio ya en tiempos de Augusto y la vicesima con Caracalla. A pesar del origen oriental de la vicesima, se trata de un modelo impositivo anclado en la tradición republicana y con un fuerte sentido jurídico, tanto en sus aspectos sustantivos como formales. Augusto, también en el ámbito fiscal, extendió el Derecho romano y sus principios hasta los confines del imperio ${ }^{71}$.

A este modelo tributario se superpuso, como consecuencia de las necesidades de un Imperio en expansión, una fiscalidad ecléctica, con aportaciones de figuras tributarias de origen oriental, ajenas por completo al universo mental romano y de difícil encaje en los moldes de sus procedimientos legales: Tributos en los que se confunden el pagador y el receptor, en los que no existe hecho imponible, con cuota indeterminada, con base en relaciones de derecho privado o penal, con carácter punitivo o confiscatorio. Destinados en un principio a la imposición provincial, fueron contaminando el sistema tributario en su conjunto, aunque sin llegar a borrar los límites con la vieja fiscalidad cívica. Es más, estos tributos foráneos fueron a su vez contaminados por normas de Derecho romano que les aportaron una naturaleza jurídica de la que solían carecer. Buen ejemplo de ello es la regulación de los bona damnatorum.

En resumen, a lo largo del alto Imperio se va configurando un sistema tributario híbrido, complejo, de raíces romanas y orientales, con rasgos de fuerte juridicidad y al mismo tiempo con anomalías en su naturaleza jurídica y procedimental.

\section{BIBLIOGRAFÍA}

C. ANDO, Imperial ideology and provincial Loyalty in the Roman Empire, Berkeley, 2000.

71 C. Ando, Imperial Ideology and Provincial Loyalty in the Roman Empire, Berkeley, 2000, p. 409. Cf. también, en este sentido, T. Honoré, Emperors and Lawyers, Oxford, 1994, p. 1 
A. ANDREADES, A History of Greek public Finance, Cambridge, Mass.,1933.

I. ARNAOUTOGLOU, Ancient Greek laws a sourcebook, Londres-Nueva York, 1998.

B. BIONDI, Sucessione testamentaria e donazione in Roma antica, Milán, 1955.

A. BISCARDI, Diritto Greco Antico, Turín, 1982.

A. K. BOWMAN, «The crown-tax in Roman Egypt», BASP, 4, 1967.

P. A. BRUNT, «The Fiscus and its Development», Journal of Roman Studies, 1966.

E. CAVAIGNAC, Population et Capital dans le monde mèditerranéen antique, París, 1923.

CHEN LI WANG, «Taxation and Empire: From Cicero to Augustus.» WWW.stanford.edu/chenliw/school/ihum31brp.pdf. 5 de abril de 2005.

L. CLERICI, Economia e finanza dei Romani, Bolonia, 1934.

J.P. CORIAT, Le Prince Legislateur, Roma, 1997.

N. D AMATI, «Natura e fondamento del tributum romano», Ann.Fac.Giur. Bari, XVI, 1962.

F. DE MARTINO, Historia económica de la antigua Roma, Madrid, 1979.

F. DI RENZO, La Finanza Antica, Nápoles,1955.

Studies, Cambridge, 1982.

A. FERNÁNDEZ DE BUJÁN, Derecho Público Romano. Recepción, jurisdicción y arbitraje, Madrid, 2007.

R. FERNÁNDEZ GONZÁLEZ, «Casio Dion y los motivos (¿fiscales?) de la concesión (¿universal?) de la ciudadanía romana», en Koinós Logos. Homenaje al profesor José García López, E. Calderón, A. Morales, M. Valverde (eds.), Murcia, 2006

P. FERNÁNDEZ URIEL, «Algunas precisiones sobre el sistema fiscal romano», Espacio, Tiempo, Forma, 1995.

P.FERNÁNDEZ URIEL: «Un fundamento en la economía de los Estados Modernos: El Sistema tributario romano. (Alto Imperio)» Aportación romana a la formación de Europa: Naciones, lenguas, culturas. Segundo coloquio de la Asociación Interdisciplinar de Estudios Romanos (AIER) 2004.

M. FINLEY, The Ancient Economy, Berkeley, 1999.

M. GAGARIN, The Cambridge companion to ancient Greek law, Cambridge, 2005.

P. GARNSEY, «Taxatio and Pollicitatio in Roman Africa», Journal of Roman Studies, 61, 1971.

A. R. HANDS, Charities and social aid in Greece and Rome, Cambridge, 1968.

E, M. HARRIS, Democracy and the rule of law in Classical Athens essays on law, society, and politics, Cambridge, 2006.

F.M. HEICHELHEIM, Historia Económica y Social de Roma, Madrid, 1982.

T. HONORÉ, Emperors and Lawyers, Oxford, 1994.

K.HOPKINS, «Taxes and Trade in the Roman Empire», Journal of Roman Studies, 70, 1980.

A.H.M. JONES, «The Aerarium and the Fiscus», Journal of Roman Studies, 40, 1950.

T. KLAUSER, «Aurum Coronarium», Reallexikon für Antike und Christentum, 1, 1959.

D. KOKKINI-IATRIDOU, Introduction au Droit Hellenique, Deventer, 1969.

C. LACOMBRADE, «Notes sur I Aurum Coronarium», Revue des Ėtudes Anciennes, 51/1-2, 1949.

J. LE GALL, J. y M. LE GLAY, El Alto Imperio, desde la batalla de Actium hasta la muerte de Severo Alejandro, Tres Cantos, 1995.

V. G. I. LUZZATTO, La riscossione dei tributi in Roma e l'ipotesi della proprietà sovrana, Atti del Congreso di Diritto Romano di Verona, 1953.

F.MILLAR, «The Fiscus in the First Two Centuries», Journal of Roman Studies, 53, 1 y 2, 1963.

F. MILLAR, The Roman East, 31 bC - aD 337. Cambridge (Mass.) y Londres, 1993.

T.MOMMSEN, Historia de Roma, 2 vols., Madrid, 2003.

J. L. MURGA, Derecho romano clásico II. El proceso, Zaragoza, 1989.

E. NARDO Y D. FALCIANI,» II Sistema Tributario dell antica Roma.

Prima parte», Rivista della Guardia di Finanza n.2, 1999. 
E. NARDO y D. FALCIANI, «ll sistema tributario dell'antica Roma.

Seconda parte», Rivista della Guardia di Finanza n.6, 1999.

L.NEESEN, Untersuchungen zu den direkten Staatsabgaben der Römischen Kaiserzeit, Bonn, 1980.

C. NICOLET, Tributum. Recherches sur la Fiscalité Directe sous la Republique Romaine, Bonn, 1976.

C. NICOLET, Roma y la conquista del mundo mediterráneo. Vol. 1, Las estructuras de la Italia romana, Barcelona, 1982.

A. ORTEGA CARRILLO DE ALBORNOZ, Derecho Privado Romano, Málaga, 2007.

L. RIBÓ DURÁN, Diccionario de Derecho, Barcelona, 1987.

L. RODRÍGUEZ ÁLVAREZ, «Notas en torno a la Lex lulia de vicésima hereditatium», Memorias de Historia Antigua, III, Oviedo, 1979, pp. 199-215.

M.ROSTOVTZEFF, Historia Económica y Social del mundo Helenístico, 2 vols.,Madrid, 1967.

M. ROSTOVTZEFF, Historia Económica y Social del Imperio Romano, Madrid, 1967.

W. SCHUBART, "Zum Edikt über das Aurum Coronarium», Archiv für Papyrusforschung und verbandte Gebiete, 14, 1941.

E. STOLFI, Introduzione allo studio dei diritti greci, Turín, 2006. C.H.V. SUTHERLAND, «Aerarium and Fiscus during the Early Empire», Journal of Philology, 66, 2, 1945. 